\title{
Imposed Work of Breathing During High-Frequency Oscillation: I Don't Mean to Impose ... .
}

Ideally, care of the neonatal or the pediatric patient who is critically ill with respiratory failure would include a treatment strategy that minimizes lung injury, preserves respiratory muscle function, and provides adequate patient comfort. The physiologic rational for high-frequency, lowvolume ventilation is sound, and one would expect to see improved outcomes. Indeed, some clinical data exist that outline the superiority of high-frequency oscillatory ventilation (HFOV) to conventional ventilation in premature infants ${ }^{1,2}$ and pediatric patients. ${ }^{3}$ However, these data were obtained from subjects enrolled in studies before widespread adoption of lung-protective conventional ventilation, and, therefore, the superiority of HFOV to current ventilation strategies is not well understood. ${ }^{3}$ Analysis of recent adult data, at best, has demonstrated equivalence between HFOV and conventional ventilation in subjects with ARDS..$^{4,5}$ Nonetheless, the application of HFOV as a rescue modality of ventilation has remained an important tool for the intensive care clinician who is caring for children. ${ }^{6}$ However, preservation of respiratory muscle function has become an important concept in mechanical ventilation. The level of inspiratory effort has been associated with the duration of ventilation ${ }^{7}$ and spontaneous breathing during mechanical ventilation may be a modifiable risk factor in the outcomes of neonatal and pediatric acute respiratory failure. ${ }^{8}$ Therefore, the interaction of spontaneous breathing, as well as ventilator imposed work load and preservation of mean airway pressure, with HFOV is important.

In the current issue of Respiratory CARe, Bordessoule et $\mathrm{al}^{9}$ presented data from an in vitro investigation of infant and pediatric HFOV. The investigators sought to quantify the simulated changes in imposed work of breathing (WOB) on a model that resulted from different ventilators, pressure settings, and frequency changes during high-frequency

The authors have disclosed no conflicts of interest.

Correspondence: Craig D Smallwood PhD RRT, 300 Longwood Avenue, Bader Building 634, Boston, MA 02115. E-mail: craig.smallwood@ childrens. harvard.edu.

DOI: $10.4187 /$ respcare. 06543 oscillation. The evaluation and comparison of imposed WOB during different clinical scenarios and with different

See the Original Study on Page 1085

mechanical ventilators are important because these could help guide clinicians in prescribing care. Before discussing the findings of the article, it is helpful to briefly review WOB and the estimation thereof.

WOB is an assessment of the energy used by the respiratory muscles to overcome resistive and elastic work of the pulmonary system during the inhalation and exhalation of a breath. It is expressed as energy per unit of volume $(\mathrm{J} / \mathrm{L})$ and is often in the range of $0.3-0.6 \mathrm{~J} / \mathrm{L}$. WOB is routinely calculated separately for inhalation and for exhalation, and is subdivided into resistive, elastic, and inertial components. ${ }^{10}$ In patients who are mechanically ventilated, WOB includes physiologic and imposed work. Physiologic work refers to the work done to overcome the resistive, elastic, and inertial components of the respiratory system, including the airways, lung, and chest wall. Imposed work (imposed WOB) includes the work that is required to overcome the additional resistive load of the endotracheal tube, the breathing circuit, and the ventilator's flow-delivery system during mechanical ventilation. ${ }^{10}$ In patients who are spontaneously breathing, imposed WOB is a work load that is added to the baseline physiologic WOB and thus increases the total WOB. ${ }^{11}$ Clinical evaluation and/or estimation of WOB requires the insertion of an esophageal catheter and continuous measurement of esophageal pressure, airway pressures and volumes.

The measurement of WOB uses an established physiologic model, the Campbell diagram (Fig.1). ${ }^{12}$ Imposed WOB has been measured in other in vitro experiments during high-frequency oscillation and has been calculated based on the modified Campbell diagram ${ }^{13}$ :

$$
\text { imposed } W O B=\sum_{\text {insp }}\left(P_{\text {set }}-P_{\text {lung }}\right) \times \Delta V,
$$

where imposed WOB is the sum of the differences of the set mean airway pressure on the ventilator $\left(\mathrm{P}_{\text {set }}\right)$ and the measured pressure in the lung model (after the endotra- 


\section{EDITORIALS}

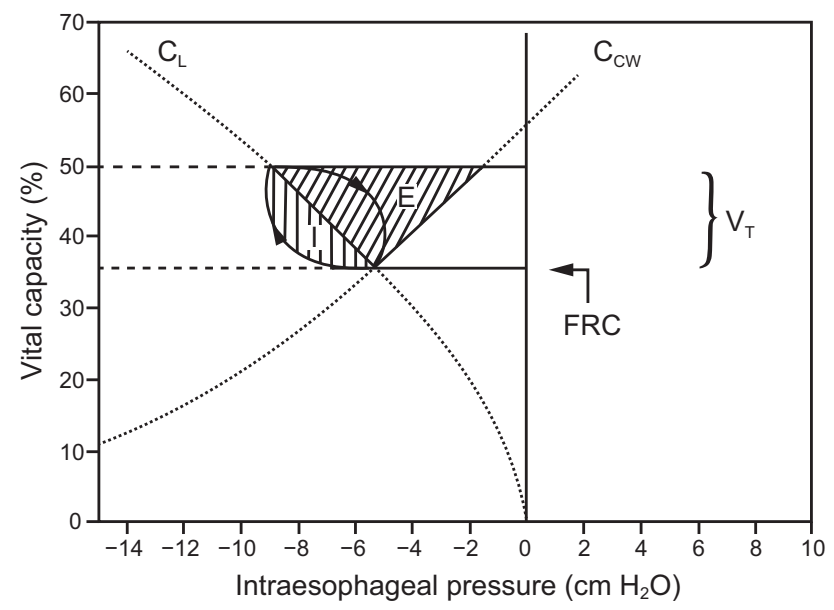

Fig. 1. FRC = functional residual capacity. A modified version of the Campbell diagram to measure the work of breathing (WOB) of a spontaneously breathing, intubated patient is constructed by plotting the intraesophageal pressure (Pes), an approximation of intrapleural pressure on the $x$-axis and change in tidal volume (VT), expressed as a percentage of vital capacity on the $y$-axis. The compliance of the chest wall (CCW) and lung (CL) are shown as dotted lines. Elastic work is the triangular area labelled ' $E$ ' and imposed work is labeled 'l'. From Reference 12.

cheal tube) $\left(\mathrm{P}_{\text {lung }}\right)$ multiplied by the change in volume. Because the lung model simulates breathing, the difference in the pressure multiplied by the volume is used to estimate the imposed work.

The pressure-time product (PTP), an index of WOB, has been used to describe changes in muscle loading and oxygen cost of breathing, wherein, the area under the esophageal pressure curve represents the magnitude and duration of an inspiratory effort. In the article by Bordessoule et $\mathrm{al},{ }^{9} \mathrm{a}$ modified experimental design is used. The investigators used PTP to compare differences in high-frequency ventilator performance during simulated breathing; however, unlike the traditional PTP clinical measurement that uses patient pleural pressure changes to predict changes in the work load, the lung model muscle pressures were preset at a fixed value and, thus, limited changes may be anticipated. The investigators calculated the PTP as the integral of mean airway pressure over time from the start of a spontaneous breath (a negative pressure deflection) until the return to baseline pressure within the test lung.

Because the PTP in this design was not calculated based on changing subject efforts per se but on changes in the mean airway pressure, this may reflect each ventilator's ability to actively respond to patient efforts and preserve the mean airway pressure in the ventilator system. ${ }^{9}$ In this case, the ideal scenario would be a ventilator that would reliably detect patient effort and render rapid flow delivery into the circuit, and result in a PTP of $0 \mathrm{cmH}_{2} \mathrm{O} \times \mathrm{s}$. Although the investigators did not note important differ- ences in the PTP among ventilators, this is a potentially useful and enlightening component of their study. ${ }^{9}$ The relative differences in PTP among the different ventilators may help clinicians to understand the rank order of imposed WOB. For instance, during the premature physiologic lung model test at $15 \mathrm{~Hz}$ (see Table 3 in Bordessoule et $\mathrm{al}^{9}$ ), the ventilators can be ordered from least to greatest PTP $\left(\mathrm{cm} \mathrm{H}_{2} \mathrm{O} \times \mathrm{s}\right)$, starting with the $3100 \mathrm{~A}$ (Vyaire Medical, Mettawa, IL) and ending with the SLE6000 (SLE Limited, South Croydon, United Kingdom). One is tempted to conclude that this demonstrates a clear difference in imposed WOB simply based on the manufacturer of the ventilator. However, this would be overstating the data because it is not clear from PTP data alone what represents a clinically important PTP value and how this would affect imposed WOB during actual ventilation.

An important consideration when interpreting the findings of the present study is that there is a paucity of normative data for PTP calculation when using the patient's own pleural pressure changes and, indeed, very limited data based on a mean airway pressure measurement within the lungs. Relative changes in imposed WOB values may be easier to compare with previously obtained physiologic WOB measurements in infants and adults. ${ }^{14,15}$ Bordessoule et al ${ }^{9}$ concluded that PTP increased with the worsening of a simulated lung condition and concluded that imposed WOB increased as a result. Although a finding that total WOB, or PTP as a rough surrogate, would increase as lung condition worsens, it may not be clinically prudent to classify this as solely imposed work. Importantly, because the investigators did not use an estimate of esophageal measurements, which itself is an estimate of intrapleural pressure, the capacity to attribute changes in PTP to imposed work versus total work is reduced. Another consideration is the contribution of imposed work during inhalation and exhalation. In the current study, PTP was computed only during inhalation. The investigators are wise to focus on this aspect of imposed WOB because the bulk of perceived imposed work during HFOV is likely a result of inadequate flow demand during spontaneous effort. However, if the investigators continue this work, it would be important to measure imposed WOB during exhalation as well.

In general, the findings outlined in the present study suggest that total inspiratory PTP increases and improves our understanding of the ventilator's role in adding to causal respiratory failure. Valves open and close rapidly, and flow control valves open and close rapidly, which result in some level of imposed work both during inhalation and exhalation. Importantly, the work of Bordessoule et $\mathrm{al}^{9}$ should be extended to evaluate for the difference in inhaled and exhaled WOB, and also to 


\section{EDITORIALS}

compare with imposed WOB during conventional ventilation.

Craig D Smallwood PhD RRT

Division of Critical Care Medicine

Department of Anesthesia, Critical Care and Pain

Medicine, Boston, Massachusetts

Robert M DiBlasi RRT RRT-NPS FAARC Seattle Children's Hospital

Seattle, Washington

\section{REFERENCES}

1. Sun H, Cheng R, Kang W, Xiong H, Zhou C, Zhang Y, et al. Highfrequency oscillatory ventilation versus synchronized intermittent mandatory ventilation plus pressure support in preterm infants with severe respiratory distress syndrome. Respir Care 2014;59(2):159-169.

2. Cools F, Offringa M, Askie LM. Elective high frequency oscillatory ventilation versus conventional ventilation for acute pulmonary dysfunction in preterm infants. Cochrane Database Syst Rev 2015(3): CD000104.

3. Arnold JH, Hanson JH, Toro-Figuero LO, Gutiérrez J, Berens RJ, Anglin DL. Prospective, randomized comparison of high-frequency oscillatory ventilation and conventional mechanical ventilation in pediatric respiratory failure. Crit Care Med 1994;22(10):1530-1539.

4. Young D, Lamb SE, Shah S, MacKenzie I, Tunnicliffe W, Lall R, et al; OSCAR Study Group. High-frequency oscillation for acute respiratory distress syndrome. N Engl J Med 2013;368(9):806-813.

5. Ferguson ND, Cook DJ, Guyatt GH, Mehta S, Hand L, Austin P, et al; OSCILLATE Trial Investigators; Canadian Critical Care trials Group. High-frequency oscillation in early acute respiratory distress syndrome. N Engl J Med 2013;368(9):795-805.
6. Pediatric Acute Lung Injury Consensus Conference Group. Pediatric acute respiratory distress syndrome: consensus recommendations from the Pediatric Acute Lung Injury Consensus Conference. Pediatr Crit Care Med 2015;16(5):428-439.

7. Goligher EC, Dres M, Fan E, Rubenfeld GD, Scales DC, Herridge MS, et al. Mechanical Ventilation-induced Diaphragm Atrophy Strongly Impacts Clinical Outcomes. Am J Respir Crit Care Med 2018;197(2):204-213.

8. Glau CL, Conlon TW, Himebauch AS, Yehya N, Weiss SL, Berg RA, Nishisaki A. Progressive Diaphragm Atrophy in Pediatric Acute Respiratory Failure. Pediatr Crit Care Med 2018;19(5):406-411.

9. Bordessoule A, Piquilloud L, Lyazidi A, Moreira A, Rimensberger PC. Imposed work of breathing during high-frequency oscillatory ventilation in spontaneously breathing neonatal and pediatric models. Respir Care 2018;63(9):1085-1093.

10. Banner MJ, Jaeger MJ, Kirby RR. Components of the work of breathing and implications for monitoring ventilator-dependent patients. Crit Care Med 1994;22(3):515-523.

11. Banner MJ, Kirby RR, Blanch PB. Differentiating total work of breathing into its component parts. Essential for appropriate interpretation. Chest 1996;109(5):1141-1143.

12. Blanch PB, Banner MJ. A new respiratory monitor that enables accurate measurement of work of breathing: a validation study. Respir Care 1994;39(9):897-905.

13. van Heerde M, van Genderingen HR, Leenhoven T, Roubik K, Plötz FB, Markhorst DG. Imposed work of breathing during high-frequency oscillatory ventilation: a bench study. Crit Care 2006;10(1): R23.

14. Liptsen E, Aghai ZH, Pyon KH, Saslow JG, Nakhla T, Long J, et al. Work of breathing during nasal continuous positive airway pressure in preterm infants: a comparison of bubble vs variable-flow devices. J Perinatol 2005;25(7):453-458.

15. Banner MJ, Kirby RR, Blanch PB, Layon AJ. Decreasing imposed work of the breathing apparatus to zero using pressure-support ventilation. Crit Care Med 1993;21(9):1333-1338. 